\title{
EL ESPACIO DE «LO POLÍTICO» EN ABENSOUR COMO POSIBILITADOR DE UNA «DEMOCRACIA SALVAJE»" ${ }^{1}$
}

\author{
BORJA CASTRO-SERRANO \\ Universidad Andres Bello (Santiago de Chile)
}

\begin{abstract}
RESUMEN: Bajo la Filosofía política crítica de Abensour y su relectura de los clásicos políticos modernos -específicamente del joven Marx - se pretende construir una postura de «lo político» que amplía el espacio filosófico y político actual. Esa lectura perfila como primer elemento la idea de que la política tiene una condición de irreductibilidad. Es pensar una filosofía de las cosas políticas mismas, la cual impone una necesidad de humanidad en la dimensión política, no siendo posible reducir lo político a otro asunto. Y si lo político es irreductible y está amarrado a una condición de humanidad, ¿es el Estado la figura que mejor se impone para pensar esta nueva configuración? Así, como segundo elemento, Abensour nos sugiere repensar la matriz del Estado, pudiendo realzar el lugar de lo político como exceso (irreductible) que redescubre la especificidad de la democracia bajo el lema de una «democracia salvaje».
\end{abstract}

PALABRAS CLAVE: Filosofía política, Abensour, democracia, crítica, humano.

\section{"The political» sphere in Miguel Abensour as a possibility for a "salvage democracy»}

ABSTRACT: Under the Critical political philosophy by Abensour and his continuous reading of the modern political classics - specifically of the young Marx-, it is intended to build a position of the "political» conceptual space which extends the current political and philosophical space. Readings of «political» as the first element highlights the idea that politics are a condition of irreducibility. It aims at speculating a political philosophy of things themselves, which imposes a need for humanity in the political dimension, which makes it impossible to reduce politics to other matters. And if politics is irreducible and it's tied to a condition of humanity, Is the State the best figure to create this new configuration? As a second element, Abensour suggests rethinking the State matrix and enhancing the place of politics as excessive (irreducible) which rediscovers the specificity of democracy under the rubric of a "wild democracy».

KEY WORDS: Political philosophy, Abensour, democracy, criticism, human.

\section{EL ITINERARIO}

Una de las muchas cuestiones que los pensadores políticos modernos se preguntaron fue cómo dejar atrás las concepciones religiosas cristianas que concebían a los hombres como ángeles. Su interrogante se instala en el paso de un hombre bestia a un ser humano (Maquiavelo) ${ }^{2}$, lo que comienza a delinear una

1 Artículo basado en uno de los temas de la tesis doctoral obtenida en la Universidad de Murcia (2014), bajo la dirección del Dr. Patricio Peñalver Gómez.

2 Cfr. Villacañas, Berlanga, J. L., «Presentación: Perspectivas de la filosofía francesa» en Daimon Revista Internacional de Filosofía, Murcia, nº 46, 2009, p. 8. 
idea de hombre moderno, soberano y autónomo. Ahí surge la interrogación de cómo convivimos entre nosotros, cuestión que la filosofía moderna quiso resolver mediante la política.

Se vislumbra un terreno fértil para la política, pero aparece una segunda pregunta: ¿para qué tipo de política? Así fue cómo en el transcurso del pensamiento moderno, si bien se pretende la libertad del hombre y su potenciación, también se hace surgir una figura que pueda reunir a todos los individuos desde sus individualidades y así controlar su convivencia: el Estado.

La cuestión decisiva en este artículo es si podemos esbozar una lectura política que permita otra entrada a las mismas dos preguntas anteriores: ¿desde qué tipo de política queremos reflexionar como hombres respecto a nuestra convivencia actual? Y es aquí que Miguel Abensour nos permite construir con su filosofía una lectura política que relee a los modernos - basándose en el joven Marx- logrando ampliar el espacio conceptual filosófico y político actual. Y esto lo hace incorporando múltiples «filiaciones filosóficas» del siglo XX —desde Clastres, Lefort, Arendt, los representantes primeros de la Teoría Crítica, hasta Lévinas - haciendo resonar una reflexión armoniosa que «en todas estas perspectivas despuntan elementos para el "redescubrimiento de la política" contra toda empresa reduccionista ${ }^{3}$.

Ya lo explicita José Luis Villacañas ${ }^{4}$, pues expone que lo central del concepto de la filosofía de Abensour está en que para pensar nuestra convivencia, para «ir más allá del bestial humano», no es posible hacerlo al margen de la política. Y para Abensour esto significa dos cosas al mismo tiempo, y aquí lo central: primero, que el solo hecho de tener que vivir juntos nos transforma en seres humanos; segundo, que la política es un ámbito que concierne a la dimensión más profunda de la condición humana. Por lo tanto, es la política la que debe poner en juego el acto de crítica y denuncia en su máxima potencia respecto a todo aquel intento por anular lo humano, pues acto seguido, también se anula lo político.

En esta línea, Abensour retoma a Arendt y la cuestion totalitarismo, pues este último en su intento por politizarlo todo, lo que más bien articula ahí es lo contrario: pura despolitización dejándonos clavados en el «estatuto de bestias». También se dejan leer resabios de Lefort, ya que el totalitarismo como destrucción del campo político pone en juego una posibilidad de redescubrir lo político, pues las nociones anteriores de la política nos han llevado a ese mismo acto totalitario y de dominación. Acto que de inmediato elimina la posibilidad de vivir juntos ${ }^{5}$.

3 Gutiérrez, C., «¿La crisis levinasiana de la Filosofía política crítica de Miguel Abensour?» en Problemas y debates de la tradición y la actualidad de la filosofía política, Raffin, M. y Podestá, B. (Eds), San Juan, Editor effha, 2012, p. 85.

4 Cfr. Villacañas Berlanga, J. L., op. cit., p. 9.

5 Habría que precisar que tanto Arendt como Lefort están circulando constantemente en la obra de Miguel Abensour. Cuando los retomamos están leídos desde Abensour. 
Así pues, nuestra lectura de lo político tendrá que perfilar como primer elemento su condición de irreductibilidad. «(...) estamos ante una misma determinación: recobrar, reconquistar la irreducible heterogeneidad de las cosas políticas (...)» $»^{6}$. Primera idea que ya implica un nuevo retorno de las cosas políticas en tanto ellas pueden irrumpir en el presente no tomando los mismos caminos que ya tomaron alguna vez — como las vías inéditas post-totalitarias-, lo que no implica un retorno $a$ la clásica filosofía política.

El intento es pensar una filosofía de las cosas políticas mismas, la cual impone una necesidad de humanidad en la dimensión política, no siendo posible reducir lo político a otro asunto. Esta dimensión de lo político en su irreductibilidad siempre está excedida, por eso no se puede reducir ${ }^{7}$. Se aprecia la intención de darle un nuevo aire a la filosofía política. Dejemos hasta aquí este tema de lo irreductible de lo político para retomarlo más adelante.

Entonces, si el espacio de lo político es irreductible y está amarrado a una condición de humanidad, ¿ es el Estado la figura que mejor se impone parapensar la configuración de la política desde nuestra construcción de la clave política? Aquí tenemos que considerar el segundo elemento de nuestra clave política. Como nos dice nuevamente Villacañas, comentando a Abensour: «La política es antes un asunto de la sociedad que del Estado» ${ }^{8}$. Pareciera que lo que une a las personas en una sociedad no es la figura jerárquica y vertical del Estado, sino otros elementos. Pierre Clastres y sus investigaciones antropológicas políticas de las sociedades primitivas nos entregan dispositivos de análisis

6 Abensour, M., «Presentación de los Cahiers de philosophie politique» en Para una filosofía política crítica: Ensayos (en adelante PUFPC). Barcelona: Anthropos, 2007, p. 9.

7 Abensour, M., «¿De qué regreso se trata?» en PUFPC cit., pp. 12 y 14. Puede aquí surgir la pregunta: si existe una política no humana, qué sería lo que excede a esta nueva política que intenta mostrar Abensour. Si bien estas cuestiones se irán desarrollando durante el artículo, creemos pertinente mostrar la afiliación abensouriana con Lévinas para aclarar este asunto: Abensour interroga fuertemente algunos textos filosóficos-éticos y otros más políticos de Lévinas extrayéndoles aquellas lecturas políticas que le son atingentes a su filosofía y que en este artículo se dejan entrever con fuerza: la importancia para Abensour respecto de la relación que debe haber entre lo humano (no puro conatus essendi sino la instalación de un sujeto que en su unicidad es responsable por el otro perdiendo él su importancia; ahora hay un pensamiento, una racionalidad que comienza desde un para-otro) y lo político (en tanto cálculo, pero como posibilidad de hacer justicia desde una nueva institucionalidad que repiensa el origen del Estado desde lo humano) para no caer en totalitarismo donde lo humano y lo político se separan. Lo político no puede olvidar desde dónde proviene, no puede olvidar lo humano en su afán de poder y cálculo, porque al olvidar la alteridad del otro hombre se ejerce tiranía. Lo político siempre está excedido por su fundamento humano. No obstante, esta nueva política que no olvida al otro, permite la instalación de la justicia como fundamento de la conciencia, lo que «reduce» esa responsabilidad ética primera, y puede así resolver y dirimir los conflictos - siempre presentes- entre los hombres. Cfr. Abensour, M., «La extravagante hipótesis» en PUFPC cit., pp. 289. Cfr., LÉvinAs, E., Entre nosotros, Ensayos para pensar en otro, Valencia, Pre-textos, 1993, pp. 134 y ss. Pp. 277; Lévinas, E., «Paix et proximité» en Les cahiers de la nuit surveillée, n³, Verdier, 1984, pp. 339-346.

8 Cfr. Villacañas Berlanga, J. L., op. cit., p. 9. 
interesantes. No es la figura de Estado fundada en la modernidad la que nos une, pues esa institución muchas veces termina por generar una dominación del hombre sobre el propio hombre, tal como se vio en los totalitarismos del siglo xx. El Estado, paradójicamente, construye comunidad desde una lógica de lo «común», subsumiendo toda diferencia.

Tal vez tampoco es el Estado que se prefigura en la actualidad, ese Estado de derecho que se instala en la democracia actual. Abensour sugiere pensar lo político no exclusivamente desde la matriz del Estado, lo que tampoco implica que su filosofía se base en una anarquía tradicional o a partir de una crítica a la dimensión política, sino que todo lo contrario, se propone repensar el Estado justamente realzando el lugar de lo político mediante el redescubrir la especificidad de la democracia.

Ya logrando conjugar los dos elementos descritos anteriormente - puntualizando que estas ideas filosóficas de Abensour se encuentran en los primeros escritos del joven $\operatorname{Marx}^{9}$ - , se deja aparecer la postura abensouriana de una Filosofía Política crítica que nos permite mostrar otro pensamiento político. Al intentar darle un nuevo lugar a lo político pensándolo ya fuera de la lógica del Estado se generan múltiples significaciones; y Abensour lo hace interrogando de modo hiperbólico ciertos textos filosóficos. Él aplica su gesto crítico tomando y descubriendo otros gestos críticos que lo ayudan a diseminar este lugar de lo político como irreductible que deja al Estado solo reducido a un momento de nuestra convivencia, logrando hacer surgir esta «necesidad de la humanidad» ${ }^{10}$. El gesto crítico en su filosofía política es un resguardo de lo que siempre debe permanecer según Abensour: la emancipación humana.

En nuestra territorialización de la lectura política veremos cómo es que interrogando, en un primer momento los textos de Marx, y luego, en un segundo momento, los textos de Clastres, Lefort, Arendt, Adorno y Lévinas, es que se permite Abensour visualizar nuevas formas de sociedad y criticar las horrorosas consecuencias de las formas totalitarias, ubicando ahí un espacio donde se puede resituar lo político desde una vinculación con lo humano; redefiniendo y redescubriendo lo político, y a su vez, la libertad y la democracia $^{11}$.

\section{Abensour lector de Marx: ¿La democracia contra el Estado?}

Si bien el filósofo alemán —según Abensour- en sus inicios políticos estaba en sintonía con pensar para Alemania el modelo político francés de la

9 Abensour, M., La Democracia contra el Estado (en adelante LDCEE), Buenos Aires, Ed. Coligue, 1998. Versión francesa: La Démocratie contre l'État. Paris: Éditions du Félin, 2004.

10 Gutiérrez Olivares, C., op. cit., p. 87.

11 Abensour, M., “¿De qué regreso se trata?» en PUFPC cit., pp. 13-14. 
democracia, modelo que ya estaba siendo pensado y que se había instalado en los escritos de otro filósofo político de mitad del siglo XIX como Tocqueville, podemos decir que el tránsito de su pensamiento político es más complejo que esto.

Si ya en La Crítica del Derecho del Estado de Hegel de $1843^{12}$ - pero no publicado hasta en 1927- exponía Marx los alcances enigmáticos que tenía la democracia, más enigmático era cuando sostenía la tensión que había entre Estado y democracia: «(...) Los franceses modernos han interpretado esto en el sentido de que en la verdadera democracia el Estado político desaparece» ${ }^{13}$.

El tema de lo político y de la democracia era un tema de la época. Tocqueville — por ejemplo— pretendía resolver el enigma de la democracia insertándola en el mismo sentido del Estado para calmar su fuerza indomable y «salvaje». Pero Marx tomaba otra dirección para pensarla. Aquí lo interesante de mostrar es que Marx ya en 1843 hizo entrar en una crisis lo político, y pensó de modo inversamente proporcional la democracia y el Estado. Pero, ¿esto implicó un alejamiento de lo político en Marx? Por un lado, esta es una postura marxista que nace a partir de este texto y donde se somete lo político a lo económico. Pero, ¿es esa la única lectura posible dirá Abensour? Por otro lado, como dice Michel Henry ${ }^{14}$, ¿no se erigieron ciertas lecturas marxistas en ausencia de la referencia del joven Marx filósofo político?

Sin responder todavía, creemos que estas preguntas nos dan pie para mostrar el camino trazado por Abensour, pues pareciera que hay una posibilidad de pensar lo político y el Estado como registros diferentes, sin perder lo irreductible de lo político. Tal vez una democracia contra el Estado que justamente resguarde lo político, situándolo no en el Estado sino en relación con lo social ${ }^{15}$, "como si la manifestación misma de la democracia tuviera por efecto rebasar los límites del Estado, ir más allá, (...) extenderse al conjunto de las esferas sociales ${ }^{16}$. Compleja fórmula todavía, al igual que la de los franceses modernos. Ya llegaremos a dilucidarla de mejor manera.

12 Aquí nos referimos al texto Critique du droit politique hégélien, Paris, Éd. Sociales, 1975, siendo esta la versión francesa utilizada por Abensour. Al español se tradujo como La Crítica del Derecho del Estado de Hegel. Cfr. MARx, K., Escritos de juventud, Obras fundamentales 1, México D.F., FCE, 1982, p. 319. Este texto será capital en la lectura que hace Abensour del joven Marx, sobre todo por la crítica que hace a la modernidad política desde sus análisis de la democracia y por su tardía publicación en 1927, lo que hace —según Abensour- poder extraer otras lecturas del Marx tardío y del marxismo.

13 Marx, Critique du droit politique hégélien en Abensour, M., LDCEE cit., p. 14.

14 Hay que precisar que el texto de M. Henry es pieza fundamental en Abensour para pensar a Marx. Cfr. su versión original Henry, M., Marx I, Une philosophie de la réalité. Paris: Gallimard, 1976.

15 Aquí ya resuena al Abensour en contacto con Claude Lefort: «ya lo político y lo social forman una pareja ineludible». ABENSouR, M., «¿Por una filosofía política crítica?» en PUFPC cit., pp. 80.

16 Abensour, M., LDCEE cit, p. 14. 


\subsection{El joven Marx de la mano de Abensour}

En el método de interrogación de textos, Abensour se vuelve sobre los escritos políticos de juventud de Marx en dos momentos: el primero, de 1842 hasta el inicio de 1843; y el segundo, de 1843 a 1844 ${ }^{17}$; separados —como dirá Abensour- por la crisis de 1843, cuando se instala la crítica a lo político expuesto en el texto Crítica del Derecho del Estado de Hegel, donde se sitúa a la democracia de un modo central. Así, Abensour pretende urdir estos textos políticos y «recuperar una dimensión escondida, oculta, de la obra de Marx ${ }^{18}{ }^{18}$ que se deja ver en el intervalo (crisis) de estos años. Lo que pretende es recuperar los textos políticos del joven Marx y así alejarse de las clásicas lecturas marxistas.

Precisemos que las lecturas marxistas de la cuales pretende alejarse Abensour surgirían, por un lado, sin el conocimiento y sin referencia al pensamiento filosófico de los primeros escritos de Marx. Y por otro, al visualizar esta tensión instalada por Marx entre democracia y Estado en 1843 - al momento de la publicación en 1927-, cuando esboza su crítica a lo político en sus escritos de juventud. De este modo, una primera postura marxista aplaude y valora que Marx haya dejado atrás en su pensamiento político su especulación filosófica. Una segunda postura, aplaude que por fin Marx haya dejado la tradición del pensamiento político, logrando replegar lo político a lo económico, acallando al primer Marx político para aplaudir al Marx tardío de su teoría económica. Así - según Abensour - surge una sociología de lo político, sin autonomía propia, sino más bien en relación con lo social y lo económico.

Abensour es crítico a estas posturas y expone «que deliberadamente nos apartaremos del marxismo» ${ }^{19}$. Entonces, mostrando el inicio del camino oculto que pretende esculpir Abensour, sí podemos decir que para esta compleja tarea ocupará el texto de 1843 como obra central, pero en el primer momento se acogerá a los textos de 1842 del Marx periodista ${ }^{20}$.

17 Puede ser relevante para no extraviar el sentido de la lectura de Abensour consultar la nota ${ }^{\circ} 5$ de la versión en español de la obra. Cfr. ABEnsour, M., LDCEE cit., p. 26.

18 ABEnSour, M., LDCEE cit., p. 15.

19 Abensour, M., LDCEE cit., p. 15. Podríamos decir que la crítica a la primera postura marxista de la que pretende alejarse Abensour está basada tanto contra una tradición anglosajona (como la de John Maguire que el mismo Abensour cita), como también a la postura de Louis Althusser y su crítica a los escritos filosóficos y políticos del joven Marx (pretendiendo relevar el carácter científico del Marx tardío). Mientras que la segunda postura es dirigida contra los pensamientos críticos de lo político realizados por Horkheimer, cuando este último realiza una sociologización de lo político al poner en relación lo político como un tipo de dominación. Ahí lo político pierde su autonomía y se repliega a otras dimensiones de una sociedad. Si bien Abensour es admirador de la Teoría Crítica, en este detalle muestra su cercanía a Adorno y su distancia con Horkheimer. Cfr. Abensour, M., «Pourquoi la Théorie critique?» en Bentouhami, Hourya et alli (sous la direction de) Le souci du droit, où en est la Théorie critique?. Paris: Sens \& Tonka, 2009, p.22.

20 Los artículos de Marx periodista que fueron publicados en la Gaceta Renana desde mayo de 1842 hasta marzo de 1843. 
Se esclarece la intención de Abensour de responder a la pregunta: ¿Democracia contra el Estado? Allí pareciera que lo irreductible de lo político no se pierde por la crítica que hace Marx a lo político, sino todo lo contrario, habría una potenciación de lo político desde las nociones marxianas de democracia, instalando un contrapunto a las clásicas lecturas marxistas que acabamos de exponer. Para Abensour su tarea implica poder recuperar las lecturas políticas del joven Marx como un pensamiento potente que está en relación con la tradición moderna, por tanto, perfectamente interpretable desde su filosofía política.

Abensour relaciona este primer momento con lo que él llamó «momento maquiaveliano» en la obra de Marx. Se deja leer este momento, dice Abensour, cuando Marx, en su intento por responder a la pregunta sobre lo político, tiene un gesto similar a Maquiavelo al expresar desde la trinchera del periodismo por el «ser de la política». En una relación con la tradición moderna, Marx se pregunta por lo político mismo, por un pensamiento filosófico de lo político, por el lugar que ocupa lo político en la constitución de lo social, por la figura del Estado - que por ahora sigue en la misma idea de la tradición moderna-. «(...) Marx, en un artículo de 1842, reconoce hasta qué punto la filosofía política contemporánea, el pensamiento de la emancipación, se constituye en una relación con la tradición $»^{21}$.

Lo que hace Abensour es retomar las ideas de J.G.A Pocock ${ }^{22}$, y saca a relucir otro modelo que se ancla en Maquiavelo como fue el modelo cívico, humanista y republicano; esto hace que surja otra filosofía política moderna de esta tradición, la cual pone a lo político como lo primero y fundamental. Aquí considera tres elementos.

Primero: reactivar, en palabras de Pocock, la vita activa de los antiguos, esa vida dedicada a las cosas políticas.

Segundo: la posibilidad que la politeia satisfaga las exigencias de los hombres, pues mediante el vivere civile se recupera la idea del actuar humano, separando el orden político del natural.

Tercero: la prevalencia de una forma-república que priorice el construir un orden secular y apegado al mundo, que está en relación con la finitud temporal. Esta república estaba alejada del cristianismo.

$\mathrm{El}$ «momento maquiaveliano» implica entonces un privilegio de lo político y de la libertad, un recentramiento del dominio público sobre sí mismo, y esto era lo que Marx en 1842 celebraba de Maquiavelo, dice Abensour ${ }^{23}$.

Sin embargo, cuando irrumpe el segundo momento de análisis —en oposición al primero- el asunto se complejiza. Ahora sí, basándose fundamentalmente en el texto de 1843 ya mencionado, y en menor medida con los escritos de 1844, Introducción a la crítica de la filosofía del derecho de Hegel y Sobre la

21 ABensour, M., LDCEE cit., p. 17.

22 Abensour retoma la obra de Pocock, J.G.A., El momento Maquiavélico. Cfr. Abensour, M., LDCEE cit., p. 17.

23 Cfr. Abensour, M., La Démocratie contre l’État, Paris, Éditions du Félin, 2004, p. 36. 
cuestión judía, Abensour muestra a un Marx que hace entrar en crisis lo político pues se dirige contra el Estado dejándolo exclusivamente como un momento particular - mediante una reducción que ya veremos- de lo que Marx llamó la «verdadera democracia». Critica al Estado moderno y sobre todo al de Hegel, pues lo enfrenta a la autonomía de la sociedad civil; el Estado pierde su autonomía ganada bajo la tradición moderna. Es una «verdadera democracia» que ya no sitúa todo su poder en ese Estado moderno que se articula como un sujeto auto-creado y que genera una estructura vertical y sagrada - desde el campo de lo político- ${ }^{24}$.

Abensour se pregunta: ¿qué ocurre con el momento maquiaveliano que se había inaugurado en los primeros textos interrogados sobre el lugar privilegiado de lo político ${ }^{25}$ Se instala el gesto interrogativo magistral de Abensour, porque encuentra la posibilidad y el espacio para poder interrogar críticamente el intento marxiano por hacer desaparecer el Estado y hacer brotar el enigma de la «verdadera democracia», que es justamente donde puede insistir en la fuerza del primer momento marxiano bajo la idea de lo irreductible de lo político, y escaparse a las ya descritas lecturas marxistas.

Es en el texto de 1843 - Crítica del Derecho del Estado de Hegel- que Marx teje sus ideas sobre la "verdadera democracia» e intenta aclarar ese enigma descubierto por los franceses modernos que esbozamos anteriormente - esa democracia sin Estado-. «(...) [es] como si Marx no hubiera dejado de interrogarse sobre el enigma del fundamento de la comunidad política, del vivir-juntos de los hombres» ${ }^{26}$.

\subsection{Primer momento: el Estado Racional}

Vemos que en este primer momento tenemos a un Marx que está en sintonía con la razón impuesta por Hegel y con la tradición moderna, sobre todo con Maquiavelo y con la audacia de Spinoza (s. XvII) que intenta separar lo político de lo religioso ${ }^{27}$; cuestión que él también pretende en su época al hacer una fuerte crítica al Estado cristiano. «Las contribuciones de Marx, periodista político, (muestran) una voluntad de emancipar el Estado de la religión por la creación de una comunidad política secular y una voluntad de destruir las formas políticas del Antiguo Régimen —estructuras jerárquicas, reino de los privilegios- para sustituirlos por una república democrática sostenida sobre la igualdad política ${ }^{28}$.

Si bien esas lecturas críticas del Estado cristiano y de las políticas del Antiguo Régimen son importantes, ellas son extraíbles de modo directo de los mismos escritos marxianos y del contexto de la época, dice Abensour. Por lo tanto,

24 Cfr. Abensour, M., LDCEE cit., p. 49.

25 Cfr. Abensour, M., LDCEE cit., p. 22.

26 Abensour, M., LDCEE cit., p. 24.

27 Cfr. Abensour, M., LDCEE cit., pp. 34-35.

28 Abensour, M., LDCEE cit., p. 31. 
lo que realmente muestra aquí un «momento maquiaveliano» —en el sentido ya descrito- y de gran reactivación de la esfera política como tal, es un fenómeno enteramente nuevo que está en la base de este pensamiento racionalista y universalista: cambio radical que afecta al pensamiento político, pero a su vez, a las categorías que ordenan las determinaciones de lo real. Ahora se quiere buscar lo real en el propio lugar de la política. Parafraseando a Abensour lector de Lefort, no es un discurso político nuevo, sino que uno totalmente político. «(...) es el efecto derivado de un discurso fundador sobre la política, sobre el lugar de la política, enteramente dirigido hacia una conquista de la dimensión política, dimensión constitutiva de la humanidad $»^{29}$.

Así, al Estado Moderno se le pretende pensar ahora como un lugar del hombre —en tesis de Feuerbach—; y quedándonos con esta tesis resumida y lo descubierto por Lefort, se ensalza un nuevo Estado Moderno que quiere ser pensado por Marx como uno que quiere ir a lo político mismo, y esta es la lectura de Abensour de los primeros textos políticos de Marx.

Ahora que lo político ya se estableció como un lugar irreductible y central, ¿qué forma adquiere el Estado Racional en este lugar político? Aún en relación con la tradición moderna, pero valorando esta dimensión real de la política que debe ser trabajada desde lo especulativo o racional, Marx concibe en este primer momento al Estado como una totalidad orgánica, autónoma, de modo cercano a Hegel, pero con la diferencia de que la filosofía aquí debe poder interpretar los derechos de la humanidad y exigirle al Estado que sea el Estado de la naturaleza humana, lo cual demuestra lo relevante de darle un lugar privilegiado a lo político. De este modo, el lugar autónomo del Estado no implica pensarlo desde la lógica contractualista ni de los derechos individuales (derecho natural - racional), como tampoco en el sentido de un surgimiento empírico. Más bien, implica pensar el Estado como una forma integradora y organizada, «al punto de reconocer en la comunidad política el poder instituyente de lo social $»^{30}$.

Podemos finalizar este primer pensamiento marxiano sobre el Estado - leído por Abensour - precisando algunos puntos. Primero, entender que esta figura de Estado no es un conjunto de partes en donde lo político lo haría funcionar mecánicamente. Todo lo contrario, es un Estado que posee una estructura interior — «organismo público», «vida pública» en palabras de Marx- que es la generadora de posibilidades en las realidades existentes. Segundo, hay una intención de darle vida al Estado, de ahí la idea de «Totalidad Orgánica»,

29 Abensour, M., LDCEE cit., pp. 31-32. Son relevantes las lecturas de Abensour sobre Lefort, pues los estudios de este último sobre el filósofo florentino son su base para llegar a la idea de un campo político particular-real, el cual se deja leer en Marx y en otros jóvenes hegelianos. Cfr. Lefort, C., Les formes de l'histoire, Paris, Gallimard, 1978. Nos imaginamos que a partir de aquí es que Abensour entiende este «ir a las cosas políticas mismas» como un intento por mostrar un regreso nuevo al campo de lo político que debe ser cuidado en tanto dimensión humana, donde lo político y lo social se urden.

30 Abensour, M., LDCEE cit., p. 38. 
con órganos, movimientos, con diferencias particulares en sus unidades. Un modelo de Estado basado en las características del ser humano y en su impulso a la actividad.

Este primer pensamiento marxiano, cuando muestra sus ideas de fondo del Estado Racional, nos recalca una base metafísica de la subjetividad, por lo tanto es posible atribuir a lo político la institución de lo social. La nueva inserción de lo político en un lugar particular permite una restauración social, diría Marx. Sería un pensamiento de lo político que piensa un Estado con una cierta novedad según Abensour: si bien retoma la idea de sistema de la tradición moderna (Hegel), le suma una filosofía de la subjetividad. «Matriz especulativa hegeliana se dirá con razón. Pero hay que agregar todavía que la esfera política, que en Hegel permanece relativizada por su subordinación al saber del espíritu absoluto, es elevada por Marx a la condición de absoluto. En este sentido se podría hablar de un "absoluto político" en la huella del proyecto de los jóvenes hegelianos que quería, bajo el nombre de filosofía de la praxis o de la acción, transformar la filosofía en política (...) $»^{31}$.

Frente a este sugerente concepto de "absoluto político» que le da un lugar propio a lo político, nos preguntamos: ¿Este nuevo elemento introducido por Marx en lo político y su lógica de Estado será un augurio de cambio para pensar de otro modo lo político?

\subsection{Segundo momento: Abensour y la «vía oculta» en el Marx de la crisis de 1843}

Esta crisis comienza con la crítica al Estado Racional, y a su vez, se nombran los primeros indicios de lo que Marx llamó la «verdadera democracia». Pero para entenderla, primero se hace necesario dar cuenta de la crítica al Estado. Ésta consistía en poder sacarle aquella investidura "sagrada», que por un lado mostraba esta figura orgánica auto-determinada, que integraba toda exterioridad para estar siempre en relación consigo mismo; y por otro lado, una cierta intención de Marx de evitar que resurgiera esta estructura «sagrada» en el ámbito político — tal como aparecía en los Estados teológicos-que se configurara de un modo vertical. «(...) una vía de acceso a la crisis de 1843 podría consistir en observar la redisposición del espacio político que se opera en ella, bajo el signo de un predominio de la dimensión horizontal, de una sustitución de la verticalidad por la horizontalidad (...) escena política centrada sobre un sujeto con centros plurales y proyectándose en direcciones múltiples. Lo que Marx llama la "verdadera democracia"»32.

Abensour muestra la desacralización que hace Marx del Estado. Pero en un paso más allá, al leer el texto de 1844 Introducción a la crítica de la filosofía del

31 Abensour, M., LDCEE cit., p. 46.

32 Abensour, M., LDCEE cit., p. 49. 
derecho de Hegel ${ }^{33}$, Marx declara que no pretende una revolución radical para Alemania - pues esa revolución es de la clase burguesa-, sino una parcial, lo que implica una revolución exclusivamente política. Lo anterior implicaría para Abensour un cierto retroceso o una cierta huida de la postura marxiana de $1842^{34}$. Pero a la vez se puede hacer otra lectura: ahora Marx pretende investir de otra manera lo político. "Es por eso que el término "desinvestimiento" no conviene, y menos todavía el de borramiento de lo político» ${ }^{35}$. Es decir, no habría una exclusión de lo político, sino la posibilidad de salvar ese lugar, o bien, de leer ahí un realzamiento de lo político, no desde este Estado orgánico racional ni tampoco desde alguna revolución radical que haga perder lo político. En palabras marxianas, habría que dejar los pilares del edificio; de ahí que hable de una revolución parcial.

Entonces, según Abensour, Marx pondrá en juego una nueva manera de investir lo político a partir de un proyecto crítico a la política que le permitirá asignarle ciertos límites y así salva la dimensión de lo político. Para esto Abensour propone volver sobre el texto de 1843 - Crítica del Derecho del Estado de Hegel-, para ver lo que Marx olvidó en 1859 — cuando deja lo político supeditado a lo económico-.

Así, este proyecto crítico de la política se despliega en dos sentidos fundamentalmente: por un lado, uno socio-histórico, el cual —según Marx- muestra a un Estado moderno racional que sigue funcionando secretamente con ciertos vestigios del Antiguo Régimen de las monarquías absolutas, donde el lugar del hombre era subsumido por esta gran figura jerárquica. Aparece aquí la idea de imperfección del Estado. De otro lado, el filosófico, que denuncia al Estado porque se olvida de quién lo produce y a quién debe «cuidar»: el hombre. Es decir, ese Estado racional muchas veces se dirige contra el hombre. Hay atisbos para pensar que lo político se puede instalar - incluso- como un resguardo del hombre ante el Estado.

Podemos inferir que ya en la crisis de la política en 1843, Marx ejerce su fuerte crítica del Estado de Hegel, sin negar su cercanía con él cuando piensa el Estado racional en 1842. Sin embargo, ahora es capaz de pesquisar que aquel

33 Cfr. MARx, K., Escritos de juventud, Obras fundamentales 1, México D.F., FCE, 1982, p. 491.

34 Aquí nos referimos a la postura tomada por Marx en 1859 — que el propio Abensour pone en evidencia-, y las lecturas marxista que surgen de esta crisis de la crítica a la política. En resumen: Abensour nos quiere mostrar que esta crisis de 1843 sobre la política criticando el Estado es retomada en 1859 cuando escribe el Prólogo de la crítica de la economía política, y nos muestra que en ese texto de 1859 Marx vuelve a descentrar la política para introducirla y subordinarla a lo económico —cuestión que hace desaparecer, anular y borrar el gesto maquiaveliano- Sabemos que esta es una lectura «clásica» de Marx donde ya instala un lugar no autónomo de lo político reduciéndolo a la necesidad infra-estructural, dependiendo de las relaciones de producción (materialismo histórico). Pero según Abensour hay otras lecturas, tal como la que él realiza y que estamos analizando, lectura que para nosotros es crucial para repensar lo político y el Estado.

35 Abensour, M., LDCEE cit., p. 50. 
Estado máquina sugerido por $\mathrm{Hegel}^{36}$ es justamente lo que permite que surja un Estado que le da la espalda al ser humano, estableciéndose como una potencia extraña para el hombre mismo ${ }^{37}$.

Marx sugiere que el hombre deje de girar respecto al Estado, casi en un giro copernicano de lo político. Es sobre la base de la crítica del derecho político de Hegel que Marx - cuando escribe a Ruge en 1843- basa su proyecto crítico para pensar y «convertir a la sociedad en una comunidad de hombres proyectados hacia fines más altos, en un Estado democrático» ${ }^{38}$. Si bien esta expresión es compleja en la medida que ya nos vamos acercando a explicar la frase «democracia contra el Estado». Puntualicemos mejor que este proyecto crítico a la política instalado por Marx en la crisis de 1843 es, según Abensour, un proyecto que permite pensar un método que privilegia la hermenéutica emancipatoria y que no anula lo relevante y el entusiasmo por lo político.

Así lo expone Abensour cuando visualiza que en este método crítico marxiano se deja ver la posibilidad de situar a lo político como una imposibilidad de alejarse de las cosas políticas. Como si el gesto crítico emancipatorio —en base a un trabajo interpretativo- deja ver una verdadera significación de lo político, y entonces develar una lectura más profunda de la figura del Estado político: «(...) por el objetivo y la intencionalidad misma que lo constituye, [es como si] fuera presa de una sobresignificación, como si estuviera asediado por un horizonte insospechable situado más allá de sí mismo» ${ }^{39}$.

Aquí y ahora se visualiza más claramente dónde nos quiere llevar Abensour con la lectura del proyecto crítico marxiano de lo político: a comprender la posibilidad de que «el Estado político, confesando sus límites, puede reconocer al mismo tiempo hacia qué horizonte lo conduce el movimiento que lo excede». Movimiento al que se le puede llamar la "verdadera democracia», aunque todavía no despejemos lo enigmático que ella tiene ${ }^{40}$. En síntesis, se establece una relectura de lo político sin jamás dejarlo de lado.

Las relecturas del texto marxiano nos muestran que al instalar esta crítica de lo político — que apuntan al ícono del Estado Racional hegeliano y a poder hacer una revolución parcial de lo político- hay un desplazamiento o punto de inflexión del momento maquiaveliano que le otorga una dimensión permanente en la obra de Marx: este lugar hace imborrable lo político generando el

36 Cfr. Hegel, G. W. F., Escritos de juventud, México, FCE, 1981, pp. 219-220.

37 Cfr. Abensour, M., LDCEE cit., p. 51. Aquí se explicita la fuerte crítica de Marx a Hegel, que por razones de extensión no podemos profundizar.

38 Esta expresión de Marx está en una carta a Ruge de mayo de 1843. Expresión compleja, dice Abensour y se pregunta si Marx cuando la dijo no se había dado cuenta todavía de la oposición que iba a descubrir — siguiendo a los franceses modernos - entre democracia y Estado. Cfr. Abensour, M., LDCEE cit., p. 51, y nota 3 p. 56.

39 Abensour, M., LDCEE cit., pp. 53-54. Aquí ya vemos que Abensour hace resonar en esta idea a la intencionalidad tomada por Lévinas en Husserl, como ese pensamiento que sale de sí en la búsqueda de horizontes innombrables; pensamiento intencional que es capaz de pensar más cosas que lo que se trazó como objetivo.

40 Cfr. Abensour, M., LDCEE cit., pp. 54-55. 
descubrimiento de la «verdadera democracia». Se vislumbra que ahora es la comunidad política la que puede tener mayor apertura para lograr estimular al Estado más allá de sí mismo, pudiendo siempre buscar las figuras que nombren y hagan aparecer la emancipación humana.

Nos vamos acercando a entender el enigma que han descubierto los franceses modernos según Marx en su texto de 1843, donde «(...) en la verdadera democracia el Estado político desaparece.» Privilegio del lugar político como posibilidad de darle un nuevo sentido al Estado moderno, sentido que no puede olvidar el movimiento hacia lo humano, hacia lo otro.

\subsection{La hipótesis de lectura abensouriana}

Abensour nos ha señalado que existiría otra vía de análisis a las lecturas clásicas sobre la crisis de 1843; que si nos aproximamos al texto marxiano de 1843 con un cierto movimiento y en toda su contemporaneidad, surge una crítica que «(...) parece situarse más bien en la exacta conjunción de una crítica filosófica y de una crítica política ${ }^{41}$. Por un lado crítica política, pues permite releer la idea de política burocrática expuesta por Hegel para resignificarla y llevarla por las ideas de Marx que pretenden dar cuenta del mejor estadio de lo político: la «verdadera democracia». Por otro lado, crítica filosófica, pues expone que Hegel en sus pensamientos políticos no tenía ninguna filosofía. Más bien solo un exceso de formalismo y de representación sobre una organización política burocrática tal como la que se vivía en la época. Faltaba ese principio filosófico rector de lo real, en cuanto a la cosa política misma —como decía Lefort-; este real que no es positivo, sino que implica un tejido con lo social y el hombre mismo ${ }^{42}$. Entonces, bajo la mirada de la democracia, aparece en Marx una voluntad de emancipación real y un pensamiento nuevo de la historia ${ }^{43}$. La emancipación real implica ese gesto crítico que sería una transformación en la práctica y a su vez, en el mundo teórico. Una mirada crítica que resguarda el campo de lo político.

La hipótesis de lectura abensouriana es justamente aplicar la interpretación emancipatoria a esta crítica de la política realizada por Marx en 1843, permitiéndole pensar que «La democracia sería pues la puesta en forma, en el campo político, del método transformativo; del mismo modo, el método transformativo sería la aplicación, en el campo de la teoría, del principio democrático ${ }^{44}$. La «verdadera democracia» implica una excedencia que proviene del mismo demos total, el cual como vida práctica y llena de acciones es plural, polimorfa y masiva. Y sería esta excedencia la que le entrega un sentido al Estado moderno siempre sobresignificándolo ${ }^{45}$.

41 Abensour, M., LDCEE cit., p. 62. El paréntesis (lo) es nuestro para adecuar la cita.

42 Cfr. Abensour, M., LDCEE cit., p. 63.

43 Cfr. Abensour, M., LDCEE cit., p. 63.

44 Abensour, M., LDCEE cit., 64.

45 Cfr. Abensour, M., LDCEE cit., p. 65. 
Nos preguntamos, entonces, si este nuevo lugar de lo político quebrará con esa lógica de la Totalidad. Desde Abensour: «¿Puede percibirse aquí otro modo de totalización, que quebrantaría una lógica identitaria? En fin, ¿se mantiene la idea de sistema a pesar del cambio de sujeto o el cambio tendría por efecto vulnerar la idea misma del sistema?» ${ }^{46}$.

Abensour nos hace pensar estas preguntas sobre el terreno de la «verdadera democracia», lo que nos lleva entonces nuevamente a los franceses modernos que pensaron que en la verdadera democracia el Estado político desaparece. La verdadera democracia, al coincidir con el ir a las cosas políticas mismas, está en una relación de contraposición directa con el Estado político. Por tanto, este contraste entre Estado político y democracia implica pensar esta última sobre la ruinas de ese Estado.

$\mathrm{Y}$ en este mismo sentido es que para Abensour lector de Marx es tan relevante esta «verdadera democracia», pues ahí estaría el secreto de este «ir a las cosas políticas mismas»; o bien, para entender el lugar irreductible de lo político $^{47}$. Digamos que para Abensour lector de Marx le interesa un triangulo extremadamente sugerente entre «lo político», la «verdadera democracia» y el "gesto crítico».

La «verdadera democracia», en primer lugar, abre la pregunta por la soberanía. Marx pretende pensar la soberanía en la perspectiva del pueblo (demos), lo que conforma el estatuto de lo político. La democracia sería "como el coronamiento de la historia moderna en tanto que historia de la libertad. (...) Mejor todavía: es en el seno de la democracia donde se revela en su perfección el principio político mismo» ${ }^{48}$. La democracia permite una emancipación de lo político, situándose como paso necesario para una puesta en marcha del vivirjuntos de los hombres, alejándose de la política que se piensa bajo una relación de dominación, o bien, bajo un anarquismo que pretende negar el Estado y lo político (Moses Hess) para romper la dominación ${ }^{49}$.

46 Abensour, M., LDCEE cit., p. 65.

47 Cfr. Abensour, M., LDCEE cit., pp. 71-72.

48 ABensour, M., LDCEE cit., p. 73.

49 Abensour, M., LDCEE cit., pp. 74-75. Dos cuestiones que aclarar en este punto: primero, Abensour contrapone a su pensamiento el entendimiento de lo social como anulación de lo político que se da tanto en la anarquía como en el comunismo. Cfr. ABEnsour, M., LDCEE cit., p. 91. Segundo, resuena aquí como importante lo ya expuesto en nota $n^{\circ} 8$, donde se da cuenta de una cierta noción de hombre, de lo humano para que podamos pensar alejados de la política de la dominación e insertos en la democracia. Es un hombre que es responsable por otro, no pura ontología - está en ese conflicto por una alteridad-. Hay ahí una responsabilidad anterior a su libertad. Y esto permite una política donde la justicia es el fundamento de la conciencia, donde se privilegia una democracia que sabe que su legislación está siempre inacabada, que nunca se cierra sobre sí misma porque está excedida por los hombres que la componen rescatando la alteridad, donde nadie pierde su libertad, pues se piensa en el otro hombre. Cfr., Lévinas, E., «El Otro, la Utopía y la Justicia» en Entre nosotros, Ensayos para pensar en otro, Valencia, Pre-textos, 1993, p. 277. 
En segundo lugar, pone en el tapete la relación entre subjetividad y actividad del demos y el paso a la objetivación «constitucional» en la democracia, que según Marx, es distinta a las otras formas de Estado. Por tanto, la institución de lo político está por encima de la estructura jerarquizada de lo social. La objetivación constitucional del demos es sólo un momento del demos total. En este sentido se opera mediante la reducción de la constitución para que el proceso de la «ley» realmente sea posterior a lo humano que está en lo político mismo. La objetivación constitucional mediante reducción permite salvaguardar el demos, ese lugar privilegiado de lo político y de la verdadera democracia. Lo primero de la democracia es la relación con ese estatuto de lo político del demos y después puede reducir un momento de la democracia en constitución objetivante.

La característica anterior de la "verdadera democracia» que potencia ese carácter fundamental del demos total, implica que lo político sitúa en ese lugar el fundamento de la democracia. Por lo mismo es ésta la que excede a toda objetivación constitucional -la cual genera una objetivación que implica solo un momento de este demos total- . La verdadera democracia termina por auto-instituir una democracia de lo social ${ }^{50}$. Se hace prioritario proteger el fundamento: el hombre real, el demos total. «Se reencuentra la misma oposición, por parte de Marx, en la crítica de 1843: el pueblo tiene, siempre, el derecho incondicional de darse una nueva constitución $»^{51}$.

Sin embargo, Abensour reconoce una cierta ambigüedad de Marx por el tratamiento del tema del presente y lo finito, primera crítica y distancia del francés con Marx. Pero a renglón seguido relee a Marx para repensar la temporalidad de la democracia: queda a la luz de Abensour una cierta directriz de infinito en la democracia, ya que como existe esa imposibilidad de ser petrificada en la constitución, hay una auto-fundación permanente. «Pensar la verdadera democracia bajo el signo de la auto-fundación permanente implica pensar el pueblo según el modelo del sujeto infinito ${ }^{52}$. De esta lectura, dice Abensour, se pueden pensar dos cuestiones centrales en Marx: una, que este pensamiento anula y borra la finitud. Y la otra, que se incorpora una nueva noción temporal, la del tiempo por-venir, el infinito.

De este modo llegamos a lo que Abensour llama la excepción de la democracia, tal vez el punto de anudamiento de la fórmula de los franceses modernos: la verdadera democracia podría pensarse como el momento preciso de realzar lo político como algo irreductible. Esto sitúa al Estado como un momento particular, es decir, un Estado político que mediante la constitución ha sido reducido a un momento siempre cambiable a la luz del fundamento de la democracia: el pueblo real. «Sólo la puesta en práctica de la reducción permite

50 Cfr. Abensour, M., LDCEE cit., p. 83.

51 Abensour, M., LDCEE cit., p. 84.

52 Abensour, M., LDCEE cit., p. 87. 
una subsunción correcta que consiste en pensar un elemento particular, el Estado político, como comprendido, incluido en el todo, el demos total ${ }^{53}$.

Ahora bien, Abensour se plantea una excelente pregunta según la fórmula de los franceses modernos: ¿qué es lo que desaparece cuando desaparece el Estado en la verdadera democracia? ¿Desaparece el Estado reducido a un momento particular o el Estado político en tanto universal organizador? Pregunta que esclarece el panorama, pues lo que Marx celebra de los franceses modernos es la desaparición del Estado político en su forma organizadora y totalizante; y por lo que hemos visto eso no implica la desaparición de lo político ni tampoco del Estado en tanto momento particular de la democracia. Sin embargo, el Estado queda excedido por la fuerza democrática ${ }^{54}$.

Es en la «verdadera democracia» donde lo político alcanza su realización, pues lo social se vuelve a sí mismo sin borrar lo político. «(...) como si la reducción sobre la cual reposa la democracia tuviera por paradójico efecto, en virtud del bloqueo que ejerce, liberar la sobre-significación que habita al Estado al punto de permitir un pasaje más allá del Estado político bajo la forma de una institución democrática de la sociedad tal que el demos pueda manifestarse y reconocerse en tanto que demos en la totalidad de las esferas, siempre respetando la especificidad de cada una $»^{55}$.

La verdadera democracia sería esa figura no formal —en alusión a la crítica a Hegel— que sitúa al demos como la figura política misma que adviene. Sitúa al demos más allá de la escisión entre el ser-político y el ser-social, como el serahí humano ${ }^{56}$.

\section{AbENSOUR Y SU FILOSOFÍA POLÍTICA CRÍTICA}

A modo de síntesis, podemos decir que ya hemos visualizado la importancia del lugar político en Marx y su crítica al Estado moderno hegeliano, pero a su vez, también hemos dilucidado la relación que mantenía con la tradición moderna, según las lecturas de Abensour sobre el joven Marx. Lo anterior permite entrever su propia mirada de lo político, mostrando un intento por reconstruir una filosofía política ${ }^{57}$ para nuestra actualidad, la cual se basa principalmente en el gesto crítico que venimos constantemente resaltando.

53 ABensour, M., LDCEE cit., p. 88.

54 Se establecen vinculaciones interesantes con la frase de Lévinas que titula su artículo: «Más allá del Estado en el Estado» en Nouvelles Lectures Talmudiques. Paris: Minuit, 1996.

55 ABENSOUR, M., LDCEE cit., p. 91.

56 Cfr. Abensour, M., LDCEE cit., p. 94.

57 Cfr. Reyes Mate, «El margen de la política», Daimon Revista de Filosofía, Murcia, $\mathrm{N}^{\circ} 27,2002$, p. 10. Esto también es dicho por el mismo Abensour al cerrar la obra que estamos trabajando, La Democracia contra el Estado, cuando hace el nexo entre los análisis del joven Marx y la posibilidad de pensar una filosofía política actual en base a su propia idea de 
Si bien Abensour nos muestra que Marx fue capaz de revelar una "vía nueva» para mostrar otro modelo ${ }^{58}$ y otro lugar de lo político, uno humanitario mediante la "verdadera democracia», el mismo Abensour pretende someter a prueba su propia hipótesis de lectura de la verdadera democracia. La somete a prueba para contrastar si esta lectura del joven Marx está en la dirección de una democracia moderna o no, en el sentido de una vuelta a la pregunta por el momento maquiaveliano ${ }^{59}$ y ese lugar privilegiado para Abensour que es el modelo cívico, humanista y republicano (momento y modelo que los considera relevantes para una lectura actual de lo político).

Este paso es fundamental para distinguir los elementos de Marx que sí ayudan a Abensour y los que no, como también poder llegar a los elementos más propios de Abensour en su pregunta por los tiempos políticos actuales.

El filósofo francés somete su lectura de Marx a una exigencia de la democracia moderna que según él es relevante para saber qué camino toma esta «verdadera democracia» de Marx. La exigencia es analizada a la luz del criterio de diferenciación (pura idea de autonomía y libertad). Frente a éste, dice Abensour, que en la verdadera democracia de Marx sí existe la diferenciación de lo político y otras esferas. Sí está presente ese sentimiento moderno de libertad ${ }^{60}$, lo cual es un privilegio de lo político como dimensión propia, que coincide con la verdadera democracia y que no está amarrada a otras esferas.

Sin embargo, aparece una respuesta más problemática —e instala una distancia con Maquiavelo- cuando se visualiza la intención de unidad en la verdadera democracia de Marx. «(...) es necesario subrayar que Marx piensa la verdadera democracia bajo el signo de la unidad —es decir, permanentemente trabajada por una voluntad de coincidencia consigo misma-, y que está por lo tanto lejos de un pensamiento de la democracia como una forma de sociedad que se constituye acogiendo la división social, que se distingue por reconocer la legitimidad del conflicto en la sociedad $»^{61}$.

Marx, al ver la democracia como unidad y que coincide consigo misma, deja afuera el conflicto que es a lo que apunta Abensour con la división social. Aquí

democracia, anclada con el momento maquiaveliano que tanto privilegia. Cfr. ABEnsour, M., LDCEE cit., p. 121.

58 Marx -leído por Abensour - en esta «vía nueva» muestra su modelo, el cual va justo por un carril central entre otros dos modelos: uno que cree en la figura del Estado político como forma organizadora y dominante; y otro que cree en que hay que descentrar y romper con el Estado y el ámbito de lo político (anarquía).

59 Cfr. Abensour, M., LDCEE cit., p. 101.

60 Cfr. Abensour, M., LDCEE cit., p. 101.

61 ABEnsour, M., LDCEE cit., p. 102. Aquí Abensour retoma a Maquiavelo pues para él - como también para Lefort- Maquiavelo sería el artífice de pensar en la diferenciación de lo político privilegiando un sentimiento de libertad, pero sabiendo a su vez que existía el conflicto y la división originaria de lo social en la oposición de los grandes que quieren dominar y oprimir al pueblo, y este último que quiere libertad. Esta oposición es lo que amenaza a toda ciudad humana dice Maquiavelo. Abensour lo extrae de El Príncipe capítulo IV y el libro $1^{\circ}$ de los Discursos. 
ya tenemos una primera diferenciación entre las lecturas de Marx y el pensamiento de Abensour propiamente tal. Pero éste intenta comprender esta lectura sin conflicto y unitaria de la democracia de Marx. Lo intenta, por un lado, en el sentido que explica que esta unidad democrática en Marx no tiene lugar bajo la lógica de una totalidad orgánica, sino que ve un privilegio de la acción. Por tanto, visualiza un cierto misterio del pueblo, una indeterminación, una auto-determinación constante que entrega flexibilidad, apertura, infinitud. Pero, si bien escapa de la totalidad orgánica —en clara respuesta a la monarquía constitucional hegeliana-, Abensour no está del todo seguro de que escape a la lógica de un sistema ${ }^{62}$. Y por otro lado, también entiende a Marx al pensar esta democracia sin conflicto pues era una manera de alejarse de la tradición moderna que veía en la objetivación política esa posibilidad que la soberanía se instale en un sujeto, cuestión que Marx rechazaba pues era perjudicar al demos total ${ }^{63}$.

No obstante lo anterior, no queda zanjado del todo si Marx y sus argumentaciones siguen instaladas en un momento maquiaveliano, aunque Abensour vuelve a la línea argumental de que existe una dimensión latente de lo político en la obra tardía de Marx —-más allá del texto de 1843-. Y acto seguido, expone como si su hipótesis de lectura sobre Marx y el momento maquiaveliano quedara en una ambigüedad, cuestión que la deja estipulada al final del capítulo seis en La Democracia contra el Estado ${ }^{64}$.

Esta ambigüedad del joven Marx y el momento maquiaveliano no anula lo recorrido hasta aquí con las lecturas de Abensour; todo lo contrario, nos sigue siendo muy relevante, porque ya podemos decir que Abensour deja a Marx como un pensador de la modernidad, cuestión no menor en el sentido de la crítica que hace Marx en 1843: «gana con eso la condición de texto fundamental de la modernidad democrática ${ }^{65}$. Marx con esa crítica dio un giro importante respecto a la tradición, sobre todo por la relevancia que le dio al lugar político y a la instalación de la «verdadera democracia» para hacer desaparecer el Estado.

62 Cfr. Abensour, M., LDCEE cit., p. 103.

63 Abensour, M., LDCEE cit., pp. 103-104.

${ }^{64}$ Cfr. Abensour, M., LDCEE cit., pp. 110-117. Queremos dejar estipulado que estos análisis de Abensour no nos entregan nuevos elementos a los ya expuesto en el recorrido, pero lo dejamos puntualizado aquí para ser precisos. Abensour logra argumentar que su hipótesis de lectura de que el lugar de lo político en Marx es irreductible mediante la desaparición del Estado y la aparición de la verdadera democracia sigue estando latente en su obra, más allá que en sus textos posteriores al de 1843 la dimensión económica sea la que adquiera mayor relevancia. Para lograr este análisis toma otro texto de 1871, «Manifiesto del Consejo General de la Asociación Internacional de los Trabajadores (AIT) sobre la guerra civil en Francia de 1871 », donde estipula que Marx hace aparecer la misma problemática que en 1843, pero ahora referida a ciertos análisis de lo comunal. Así, corrobora una dimensión latente y de cierta constancia en la obra de Marx sobre lo irreductible de la política la cual debiese dirigirse contra el Estado.

65 ABENSOUR, M., LDCEE cit., p. 106. 


\subsection{Nuestra lectura de «lo politico» desde Abensour}

Desde nuestros propios análisis pareciera que Abensour en el punto crítico realizado a Marx - respecto a la unidad de la democracia-comienza a dejar entrever sus propias ideas de lo político y de la democracia, sin alejarse de las lecturas del joven Marx. El filósofo francés nos lleva a pensar el momento maquiaveliano en nuestro presente. Critica que Marx, al haber subordinado la exigencia de diferenciación a un movimiento de reconciliación lleva al pensamiento de la democracia «a una negación de la exterioridad, a un rechazo de la alteridad y a una forclusión de la finitud $»^{66}$.

La verdadera democracia en ese intento de poner en juego el imperativo moderno de autonomía y de estar siempre en una auto-fundación ilimitada, puede quedar expuesta a una dialéctica emancipatoria — según Abensour- que la convierte en su contrario: heteronomía y autodestrucción. Esto ocurriría por ese movimiento sobre sí misma que hace que la verdadera democracia no acoja la alteridad. En ese movimiento de ilimitación de la verdadera democracia al estar en una idea de unidad no ha pesquisado la fragilidad y la contingencia de las cosas humanas ${ }^{67}$, la cuestión del otro hombre al son de Lévinas.

Entonces nos preguntamos con Abensour: ¿qué queda del enigma de la verdadera democracia y lo político? Dejemos que Abensour proponga —nuevamente siguiendo al joven Marx - un campo de lo político pensado como una dimensión irreductible, que tiene vida propia mediante la democracia. Si la democracia está reconducida constantemente a la actividad del pueblo hay ahí un elemento de idealidad que piensa una relación indisoluble entre lo político y el pueblo.

Por tanto, Abensour dirá — y ahora alejándose del joven Marx— que no hay una realidad sociológica pre-existente a la institución democrática en la cual la misma democracia deba manifestarse políticamente: más bien hay una institución democrática/política de lo social que genera desde la base un plano social conflictivo en el cual lo político es la toma de decisión de la sociedad a la forma de resolver ese conflicto basal. «Idealidad, pues, ya que el ser del pueblo es un querer-ser según la libertad. Democracia y llegada a la existencia del pueblo son indisociables; la institución democrática de lo social y el nacimiento, la "invención" del pueblo, constituyen un solo y mismo acto (...) la sociedad no puede sino reconocer una existencia problemática» ${ }^{68}$.

Ese elemento de idealidad en lo político democrático es el que le da un lugar propio e irreductible a lo político. Lo político entonces puede situarse independiente de la dimensión económica ${ }^{69}$ y de las figuras institucionalizantes como el Estado; fuera de las estructuras sociales que son puro elemento de dominación.

66 ABEnsour, M., LDCEE cit., p. 106.

67 Cfr. Abensour, M., LDCEE cit., p. 106.

68 ABEnsour, M., LDCEE cit., p. 107.

69 Notables son los análisis de Pierre Clastres cuando critica al marxismo, justamente movimiento que somete lo político a lo económico. Textos que son basales para Abensour 
Contrariamente a Marx (y también a la lógica del consenso hegeliana), la posibilidad de la división de lo social y el conflicto permite pensar una democracia en donde lo político y lo social sean indisolubles. Así, lo político es respuesta articulada en relación con esa división social que siempre permanece en una democracia, la cual instaura una pura relación de libertad, pero a su vez una pura relación de fragilidad porque no hay vínculo de totalización, sino de conflicto permanente: lo humano propiamente como tal.

«Lejos de ser una realidad masiva, sustancial, homogénea y estable, lo social se encuentra amenazado, desde el origen, por la posibilidad de su desaparición y su división, como si su acontecer llevara en sí mismo la cuestión de por qué hay sociedad en lugar de nada, y al mismo tiempo, la amenaza de la nada o de la pérdida en sí» ${ }^{70}$. Por lo mismo, el ámbito de lo político como irreductible es resguardo de ese lugar originario de lo social y humano, dirá Abensour siguiendo a Lefort, siempre dejando que lo político ponga la diferencia, lo plural, el conflicto.

Se instala la transposición de Pocock del momento maquiaveliano por el camino del redescubrimiento de lo político - puro gesto crítico abensouriano- que hicieron los humanistas italianos en la vita activa y en el vivere civile. Redescubrimiento de lo político para lo que Abensour se ayuda con los pensamientos filosóficos de C. Lefort y $\mathrm{H}$. Arendt cuando interpretan que la dominación totalitaria apunta a la destrucción del dominio político.

Entonces, la crítica de la dominación totalitaria está estrechamente ligada con el intento por retornar a las cosas políticas misma ${ }^{71}$, donde lo político reconozca la necesidad de lo humano, ese fundamento frágil que hace incorporar la alteridad de lo humano. La vía de la filosofía política crítica sería la articulación entre la cuestión política y el hecho de la dominación. Es justamente ese redescubrimiento de lo político la posibilidad de crítica a la dominación totalitaria. Entonces, el redescubrir lo político es la antítesis al sistema totalitario y despunta la posibilidad de pensar la democracia ${ }^{72}$ —en tanto la idea basal de conflicto que permite pluralidad, alteridad-. "A fin de franquearse un paso a esta singularidad de la democracia, conviene no solo rechazar las ideologías del consenso, especialmente la del consenso entre democracia y Estado, sino también des-banalizar la idea de conflicto (...) $)^{73}$.

Si volvemos a esa cuestión central sobre el paso de la bestia humana al ser humano y queremos que sea en una sociedad, ésta - desde Abensour- ya es política, por tanto conlleva conflicto. Esto implica —en palabras de Villacañas- que no se puede vivir juntos sin diferenciación sino que se puede vivir

en su irreductibilidad de lo político y su «contra» el Estado. Cfr. CLASTRES, P., «La Sociedad contra el Estado» en La Sociedad contra el Estado. Santiago de Chile: Ed. Hueders, 2010, pp. 157-179.

70 Abensour, M., «¿Por una filosofía política crítica?» en PUFPC cit., pp. 80.

71 Abensour, M., LDCEE cit., pp. 121.

72 Abensour, M., «¿Por una filosofía política crítica?» en PUFPC cit., p. 88.

73 Abensour, M., LDCEE cit., p. 132. 
juntos pero separados al mismo tiempo ${ }^{74}$. «La democracia, por muy paradójico que pueda parecer, es esta sociedad política que instituye un lazo humano a través de la lucha de los hombres y que, en esta misma institución, se reencuentra con el origen (...) de la libertad» ${ }^{75}$.

Existe una nueva matriz de sentido que hace pensar en una democracia contra el Estado, la cual le confiere múltiples nuevos sentidos. Al decir de Abensour: instalación de la paradoja democrática. Democracia que en palabras de C. Lefort es «salvaje» pues no se deja dominar, y que es parte de la institución de lo social al poner en juego el conflicto siempre presente en las sociedades no permitiendo la totalización: se da así una relación estrecha entre lo político y lo social ${ }^{76}$.

«La diferencia entre el siglo xix y el xx es que el primero creía poseer, o poder poseer, la solución, mientas que el segundo hace del enigma su morada, advertido de que historia y política están destinadas a permanecer como un problema sin fin ${ }^{77}$.

Escuela de Trabajo Social, Facultad de Humanidades y Ciencias Sociales.

Av. República 252

Borja Castro Serrano

Universidad Andres Bello (Santiago de Chile)

francisco.castro@unab.cl

[Artículo aprobado para su publicación en noviembre de 2014]

74 Villacañas Berlanga, J.L., op. cit., p. 9.

75 Abensour, M., LDCEE cit., p. 132.

76 Abensour, M., «Democracia salvaje y Principio de Anarquía» en PUFPC cit., p. 273.

77 Abensour, M., LDCEE cit., pp. 11-12. 